\title{
A Neurodidactic Model for Teaching Elementary EFL Students in a College Context
}

\author{
Edwin Y. Barbosa ${ }^{1}$ \\ ${ }^{1}$ School of Languages and Communication, University of Pamplona, Pamplona, Colombia \\ Correspondence: Edwin Y. Barbosa, School of Languages and Communication, University of Pamplona, \\ Pamplona, Colombia.
}

Received: February 4, 2021

Accepted: February 24, 2021

Online Published: February 25, 2021

doi: 10.5539/elt.v14n3p42

URL: https://doi.org/10.5539/elt.v14n3p42

\begin{abstract}
The purpose of this study was to propose a neurodidactic model for the development of primary communication skills in $1^{\text {st }}$ year students of English as a Foreign Language at the University of Pamplona. Conceptually, the variables were supported upon relevant educational theories, language acquisition theoretical constructs and recent neuroeducational tenets. This was a descriptive, explanatory field, and projective research, which used a non-experimental cross-sectional design. 102 students formed the population, while the sample was randomly and representatively conformed by 62 individuals. The data collection instrument consisted of a modified Likert scale survey with 45 items. As for the reliability and validity, they were determined by expert judgment, discriminant analysis by item, as well as Cronbach's $\alpha$ reliability coefficient of 0.873 for the first and through a pilot test of 20 individuals; the second being a coefficient of 0.880 . The results indicated an averagely high didactic methodology against a very high neurodidactic methodology, obtaining a relationship between the two approaches that endorses the implementation of brain-based strategies to enhance the learning of a foreign language.
\end{abstract}

Keywords: EFL, English teaching, brain-based methods, neurodidactics, natural approach, language acquisition

\section{Introduction}

Neurodidactics can be defined as an integrated approach that optimizes human and material educational resources through the understanding of the brain functions in the acquisition process of knowledge and skills. This topical discipline derives from the amalgamation of educational neuroscience and the nature of disciplinary, interdisciplinary or transdiciplicary subject matters. From this perspective, not only are neuroeducators to comprehend the nature of their discipline, but they are also convened to identify the teaching elements and procedures that create and strengthen neural networks resulting in the development of a robust memory system. With this concept in mind, a teacher is perceived as an expert and experienced agent who is in the center of the process alongside the learner; thus neither performer should be displaced from the center of the learning process given the cause and effect nature of the educational phenomenon. In this context, Foreign Language Neurodidactics is defined as the systematic arrangement of communicative attitudes, methods, strategies, techniques, tasks and procedures that effectively bolster the learner's brain development as foreign language performance and competences are acquired.

The definition above becomes significant because learning English as a Foreign Language (EFL) has become a global mandatory requirement across academic disciplines. For this reason, a great deal of students attends colleges and institutions with the aim of developing their English communication skills so as to ensure their academic success. In so doing, learners have to deal with various difficulties as they start their college life (Reynolds and Constantine 2007); namely, emotional factors, cognitive individual variation, English orality intricacy, teaching approaches and the catatonic predisposition of professors. This generalized situation brings about consequences mainly in the academic results of first year students due to exposure to a new educational experience and setting. In the 2019 reports of the EFL Program at the University of Pamplona the academic failure and dropout rates have shown a significant surge; the average rate of students failing elementary English I was $45 \%$, whereas the dropout rate in the entire population of the Foreign Language Program was $19.4 \%$, well over the institutional and national rates. The most outstanding reasons for these results are related to the type of instruction supported by traditional methods that teachers implement and the complexity of English in terms of 
phonological and speech development. This practical crisis in the college context calls for innovative solutions in the interest of increasing the effectiveness of current methodologies. In EFL didactics little attention has been given to recent discoveries that have taken place in the field of neuroscience, which implies a paradigmatic complementation of the pedagogical methods that teachers use in the classroom. In this sense, Neurodidactics emerges as a brain-based discipline that seeks to lay the scientific foundations upon which modern didactics theories should be erected (Preiss, 2003: 39). Bransford, Brown and Cocking (2003) indicate that neuroscience is contributing to a greater understanding, and to providing answers to questions of great interest to educators; for example, there is evidence from research that both a developing brain and a mature brain are structurally altered when learning occurs. In the same way, it is possible to determine didactic actions that provide a significant improvement in learning and in general in the perception of the quality of the educational service, in contrast to procedures based on traditional paradigms. On the other hand, Grein (2013) describes the neural dispositions for individual variation and the role and functioning of neurotransmitters in the execution of cognitive mechanisms such as attention, creativeness and retention. Grein explains that right amounts of Acetylcholine trigger positive effects on attention, Glutamate fuels our sensory channels and our motor skills, the incidence of regulated Noradrenalin enhances motivation, Dopamine stimulates attention, inquisitiveness and enthusiasm and Serotonin deters feelings of fear and reinforce our memory system. This author further expands on the relevance of the neocortex and the limbic system since this latter structure filters out input via emotional parameters that determine whether they will become intake in the neocortex or overlooked in the long term memory. Despite the intricacy of the human mind, this scientific correlation represents a clear cause and effect correspondence of the external factors that affect neural activity; thus informing teachers on how to proceed didactically to create an effective learning environment.

In this respect, this study suggests that a neurodidactic model potentially contributes to endowing EFL teachers with evidence-based teaching devices in order to tackle the most rooted issues in the acquisition process of a foreign language such as fossilizable linguistic phenomena and oral fluency. Moravcová and Mad'arová's (2016) emphasized the existing of neuro-functional networks that are only specialized in processing special language aspects during the process of language acquisition. This correlation has been studied with neuroscientific advanced technology; specifically, Wang (2014) demonstrated functional specialization of the brain via Functional Magnetic Resonance Imaging (fMRI) techniques and the lateralization of brain function has been investigated through the study of lateralized brain lesions (Milner, 1971), split-brain patients (Gazzaniga, 2000), sodium amytal injection (Wada and Rasmussen, 1960), intraoperative brain stimulation (Penfield and Jasper, 1954), and neuroimaging (Petersen et al., 1989; Desmond et al., 1995). Therefore, the objective of this research was to posit a neurodidactic model for the development of primary communication skills in elementary EFL college students at the University of Pamplona in Colombia. To accomplish this goal, the author aimed to: 1) identify the didactic methods implemented by the EFL professors, 2) determine the communicative performance of first year college students, 3) analyze the cognitive implications associated with orality development and 4) design a neurodidactic model for the effective development of primary communication and linguistic skills of elementary EFL students.

Based on neuroeducational principles, Gonzalez (2016) proposed a change of pedagogical perspectives towards the teaching of the mother tongue through the Malemegra Method, which totally divested the explicit teaching of grammar. He affirms that learners can also contribute with the elaboration of their own learning since teachers may impose behavioral canons that do not activate the learning functions of an adolescent brain. Gonzalez's research is associated to this proposed model since it also advances a methodological solution using a robust educational theoretical construct authenticated by the evolution of neuroscience. Specifically, the Malemegra Method presents shared values that identify the content, the strategies, the pertinent ages and the aspects of the mother tongue that should be taught to Spanish young learners. However, as compared to his proposal, the current neurodidactic model specifies in a more in-depth fashion the techniques and strategies to be implemented in order that EFL professors can rely on diagnostic procedures that will help them put into practice neuroscientific didactic actions. Two additional distinctions can be drawn from this study; on the one hand, the fact that the academic context of higher education implies more complex cognitive traits of college students as compared to the level of abstraction, reasoning and motivation of younger learners; on the other hand, the teaching of a foreign language comprises a particular epistemic and pragmatic knowledge which is not addressed in the Malemegra Method.

Rukminingsih (2018) demonstrated through a qualitative study the relevance of neurodidactics in the implementation of a blended mode for learning EFL. Special emphasis was placed on the role of the limbic system as the brain structure that filters out information towards the neocortex based on emotional parameters. 
This center of emotions impregnates the memory system with the appropriate mental predisposition for effective learning to take place. Rukminingsih reported that irrespective of whether the lesson was grammar-based or not, students experienced positive and negative emotions; the aspects that played a major role in the learners' positive mindset and results were the attitude of the teacher, the strategy used and the inventive learning environment. The author concludes that teachers must understand the brain functions and how they affect the learners' reality so as to enhance the quality of teaching. Nonetheless, even though this qualitative study presents evidence for the effectiveness of neurodidactics through a set of activities for a class unit, it leaves room for a comprehensive model that teachers can utilize as a roadmap for identifying students' strengths and areas of improvement prior to beginning a given EFL course and for implementing teaching techniques that clearly describe systematic actions.

Another study conducted by Conkan (2018) aims at finding out to what extent teachers apply, and initiate practices discovered at teacher seminars of German as a Foreign Language and how they can be linked to the field of neuroscience and didactics at the Goethe-Institute Bucharest and its partner institutions. This author defines neurodidactics as a possible didactical method that makes usage of certain classroom activities, in order to stimulate neuronal connections and prepare the brain for learning. She hypothesized that teachers are motivated to use brain-stimulating exercises in order to create and impact the classroom atmosphere and less for their learning content. The research concludes that brain activating exercises and warm-ups play a decisive role in the sequences of any lesson. They are beneficial, because they allow a playful and subtle crossing into another learning sequence. Moreover, teachers make use of supplementary didactic materials, in order to integrate all language skills during class: reading, writing, listening-seeing and speaking. This also showcases that a "mix of methods "and different media are required to train these skills. Activities that actually prepare the brain for learning and stimulate cooperation also improve the overall learning context. The preference that teachers revealed in this study is an indicator in favor of the implementation of brain-based social-emotional strategies which steer educators towards the selection of materials that foster a responsive environment for the acquisition of a foreign language.

Consequently, the purpose of this study was to design a neurodidactic model that provides preventive, functional and corrective categories consisting of a set of strategies associated with diagnostic tools, emotional management, interpersonal treatment, motivational and operational techniques. The efficacy of this methodological proposal is compared to and contrasted with existing EFL didactic tendencies such as the grammar-translation method and the communicative approach in order to determine its suitability to address the most relevant concerns that college students deal with when initiating their learning process. As a result, language pedagogy is expected to create synergy with a more eclectic approach that is informed by brain research advancements so that the academic, social and emotional challenges of first year students can be regulated to minimum levels of occurrence; accordingly, all teaching actions should adjust in a way that they fit within the natural development of the brain. According to the author, this is one of the first EFL concrete brain-based didactic proposals that challenges and complements traditional postulates in the field of foreign language teaching.

To articulate this proposal, the projective research design was implemented as it deals with how actions should be done to achieve goals and function properly (Hurtado, 2008). Projective research involves creation, design, or drawing up plans, programs or models in order to solve a practical problem or meet a social need based on the diagnosis of the necessities, the explanatory processes or the involved causes and the future tendencies. This study is based on a systematic search and inquiry process that requires description, analysis, comparison, explanation, and prediction. From the descriptive stage, needs are identified and the phenomenon to be improved is delimited. In the comparative, analytical and explanatory stages, the causal processes that originated the current conditions of the event to be modified are recognized so that a plausible explanation of the event could predict circumstances or consequences in the event of determined alterations; the predictive stage identifies future trends, probabilities, possibilities and limitations. Based on this information, the researcher must design or create a proposal capable of producing the desired changes.

\section{Method}

\subsection{Participants}

The participants of this study were selected from a population of professors and students belonging to the Bachelor's Degree in Foreign Languages at the University of Pamplona located in Pamplona, Norte de Santander, Colombia. Namely, eight EFL professors: four teaching at the Elementary Level I and four teaching at the Elementary Level II; 102 students: 51 from Elementary Level I and 51 from Elementary Level II. Their ages ranged between 18 and 25 years. 


\subsection{Sampling Procedures}

The respondents for this research were chosen taking into account the technique used for the selection of each probability sample. By way of a simple random sampling procedure, eight EFL professors holding specializations and master's degrees were selected. On the other hand, a stratified random sampling technique was employed to extract a student sample from each gender mixed group of Elementary English I and II. To that end, the sample size was calculated, the formula used by Sierra (2005) was applied for finite populations:

$\mathrm{n}=\frac{4 . \mathrm{N} \cdot \mathrm{p} \cdot \mathrm{q} .}{\mathrm{E} 2(\mathrm{~N}-1)+4 \cdot \mathrm{P} \cdot \mathrm{q}}$

Where:

$\mathrm{n}=$ the sample size that is calculated

$4=\mathrm{a}$ constant

$\mathrm{p}$ and $\mathrm{q}=$ the probabilities of success or failure, which has a value of $50 \%$, so $\mathrm{p}$ and $\mathrm{q}=50$

$\mathrm{N}=$ the size of the population

$\mathrm{E} 2=$ the error selected by the researcher $=8 \%$

Substituting values, we have:

$\mathrm{n}=\frac{4 \times 102 \times 50 \times 50}{(8) 2 \times(102-1)+4(50) .(50)}=\frac{1020000}{6528+10.000}=\frac{1020000}{16528}=62$

$\mathrm{n}=62$ students (Total Sample)

$n=62$ students, they represent $60.78 \%$ of the population and therefore, according to the criteria of Sierra

(2005), it is a significant and representative sample.

A stratified random sample of a probabilistic type was used to obtain the sample; the population was divided into mutually exclusive and collectively exhaustive groups and then a simple random sample from the strata was selected within each stratum separately. In this regard, the calculation of the stratum of the sample proposed by Parra (2006) was carried out, from the total number of students the proportional stratified sample was derived, for which the formula of Shiffer (1987) used by Chávez (2004) was applied; it is presented below:

$\mathrm{n} 1=$ $\mathrm{nh}$ . $\mathrm{n}$

$\mathrm{N}$

Where:

$\mathrm{n} 1=$ the stratum that will be determined

$\mathrm{n}=$ adequate sample size

$\mathrm{n} \mathrm{h}=$ size of the population stratum

$\mathrm{N}=$ size of the population

The determination of the sample size for each stratum is presented below:

$\mathrm{N} 1=$ 51 x $62=0.5 \quad$ x $62=31=\mathbf{3 1}$

102

$\mathrm{N} 2=$ 51 x $62=0.5 \times 62=31=\mathbf{3 1}$

Table 1. Distribution of the sample stratification

\begin{tabular}{lll}
\hline University of Pamplona & Population & Stratified Sample \\
\hline Elementary English I & 61 & 31 \\
Elementary English II & 61 & 31 \\
Total & 102 & 62
\end{tabular}

Data was collected from the stratified sample (see table 1); thus, 102 students were scheduled to attend the RG203 and RG204 laboratories located on the 2nd floor of the Communication and Languages Department on 
the main campus of the University of Pamplona. Out of the 102, 62 students were selected using a colored numerical category by having each participant take out a random numbered slip of paper contained in a black bag. Those obtaining a red numbered slip were dismissed; the sample only consisted of those containing the blue numbered slips. The sample students and professors signed an informed consent letter by which they agreed on the unpaid voluntary nature of the data provided and were further informed of the confidentiality, integrity and responsible conduct of the researcher. Every respondent was given a hard copy of the instrument and they were asked to indicate their level of agreement from a list of items using a given pencil and eraser in a pressure-free environment.

\subsection{Data Collection Instruments and Measures}

Subsequently, the direct observation method was used by utilizing a structured format. For Volkmar (2013) it is a method of collecting evaluative information in which the estimator observes the subject in their usual environment without altering the environment. For that purpose, the observation checklist template contained a marking scale that determined the frequency of occurrence from $0 \%$ to $100 \%$ in ascending $25 \%$ intervals and the dimensions to be assessed such as the didactic and neurodidactic EFL approaches that professors used in their regular class sessions (See Appendix). On the other hand, Clauser (2007) considers that the survey "is a research instrument that consists of a series of questions and other indications with the purpose of obtaining information from those consulted". It is generally designed to perform a statistical analysis of the responses and for the purpose of this research, a statistical analysis was carried out that accounted for the causes that raised the problem outlined and the effectiveness of the neurodidactic model. Therefore, the survey used consisted of a series of ordered items that reflected the attitude of the respondents towards the didactic action and the appropriateness of the methodologies. A Likert-type scale was used with closed response alternatives and structured in 45 items, whose response categories were: Totally Agree (5), Agree (4), Undecided (3) Disagree (2), and Totally Disagree (1). These response alternatives were quantified with the aforementioned bipolar denominators, where the highest value was 5 points and the lowest value was 1 point. The items responded to the indicators reflected in the table of variables, namely: Structure, Procedures, Methods, Techniques, Strategies, Interaction, Content, Resources, Triune Brain, Whole Brain, Hemispheres and Multiple Intelligences. The internal and external validity process of the instrument was carried out through the expertise of seven research specialists both in methodology and in educational sciences, the experts examined the instrument in advance designed and proposed by the researcher to later carry out the second criterion which is its reliability. In this study the statistical method Cronbach's Alpha Coefficient (Cronbach, 1951) was used. Their values range between 0 and 1, with 0 being the value that indicates lower reliability and 1 the value that indicates total reliability, where: 0 means null reliability and 1 represents total reliability. When the alpha value is greater than 0.7 , it is considered that there is an effective internal consistency, it means that the implemented instrument was considered reliable, obtaining for the Didactic Methodology variable a score of 0.873 with a range of Very High and for the Neurodidactic Methodology variable an average of 0.880 within a Very High range. Accordingly, once the results were obtained, they were entered into a spreadsheet of the SPSS statistical program in version 22, which could be achieved directly determining the results, by implementing the following formula:

Where:

$$
\alpha=\frac{K}{K-1}\left[1-\frac{\sum S_{i}^{2}}{S_{T}^{2}}\right]
$$

$\alpha=$ Cronbach's Alpha Coefficient

$\mathrm{Si} 2=$ Sum of the variances of the items.

St2 $=$ Total Variance (Variance of the sum of the items)

$\mathrm{K}=$ Number of items of the Instrument

Once the data was entered from the dimension's subject to the Didactic Methodology variable, and replaced in the indicated formula, the coefficient to measure the reliability of the designed instrument was obtained, which after entering the data into the SPSS statistical program, was obtained the degree of reliability, which determined if it is reliable for its application. On the other hand, the scale established by Ruíz (2004) was adopted, which allowed us to qualify the magnitude of reliability in five ranges detailed in table 2 . 
Table 2. Scale of Interpretation of Cronbach's Alpha Coefficient $(\alpha)$

\begin{tabular}{lllll}
\hline \multicolumn{2}{l}{ RANGE } & & & MAGNITUDE \\
\hline From & 0.81 & to & 1.00 & Very High \\
From & 0.61 & to & 0.80 & High \\
From & 0.41 & to & 0.60 & Moderate \\
From & 0.21 & to & 0.40 & Low \\
From & 0.01 & to & 0.20 & Very Low \\
\hline
\end{tabular}

Source: Ruiz (2004)

\subsection{Research Design}

The projective design commences at the descriptive stage in which the following elements took place: identification of needs, definition of the event to be modified, study of both the demand and the desired event or intentionality, the surrounding conditions, the situation, the possibilities, the alternative proposals and the study of the offer. In addition, this proposal consisted of a mainly explanatory character through which the causal processes that originated the current conditions of the event to be modified were identified, so that a plausible explanation of the event allowed to predict circumstances or consequences. Taking into account its frame of reference and its intentionality, this study was also classified within a projective research, since the final objective was to generate a neurodidactic proposal. Thus, this was a field descriptive, explanatory, and projective study, which used a non-experimental cross-sectional design.

\section{Data Analysis}

Descriptive and inferential statistics were used as analysis tools, considering the means achieved by the indicators, dimensions and variables according to the population stratum. Therefore, the data was processed in an Excel spreadsheet, through the SPSS program for Windows, standard version 20.0 in Spanish; on the sheet, the total of points grouped in each item, indicator, dimension and variable were observed for subsequently establishing the aforementioned statistics. Within the same context, the arithmetic mean, the mode and the median were used allowing the categorization of items, indicators and dimensions as well as the study variables, this was done through matrix tables. First, to provide an analysis of the results, the data was processed through a scale, so that the characteristic of the variable could be identified by operating the dimensions and indicators, taking into account the selected analysis categories and the interval. Therefore, the scale was developed using the measurements of the values assigned to the response alternatives of both frequency denomination and agreement (according to the Likert scale), thus adopting the procedure of Pérez (2012). To determine the Total Interval (It) of the scale, it was necessary to select the highest value that the instrument contained, in this case it corresponded to number five (5); this being the highest score (XM) and the lowest score, number one (1), for the values with the lowest score $(\mathrm{Xm})$. Subsequently, the result was divided by the number of response alternatives, which for the case corresponded to five, as observed in the following equation:

$$
I t=\frac{X_{M}-X_{m}}{A R}
$$

Substituting values, we have:

$$
I t=\frac{5-1}{5}=\frac{4}{5}=0,80
$$

Table 3. Variable Analysis Scale: Neurodidactic Methodology

\begin{tabular}{ll}
\hline INTERVAL & ANALYSIS CATEGORY \\
\hline $4.21<5.00$ & Very High \\
$3.41<4.20$ & High \\
$2.61<3.40$ & Averagely High \\
$1.81<2.60$ & Low \\
$1.00<1.80$ & Very Low
\end{tabular}

The application of the instruments to the respective sample of the population in question was conducted in order to establish the validity of the instrument. In addition, the statistical analysis of the items was carried out to obtain the orientation of the answers given by the selected sample; following this, the tabulations and analysis of 
the research results were carried out with their respective discussion and theoretical contrast. Once the data from the survey applied were collected, tables are presented with the data for each of the indicators, dimensions and variables, as well as the correlations of the variables. Once the results were calculated, the discussion focuses on the interpretive analysis based on the theoretical basis developed in this research.

Table 4. Dimension: Didactic methodology for EFL teaching

\begin{tabular}{|c|c|c|c|c|c|c|}
\hline \multirow{3}{*}{ Indicator } & \multicolumn{5}{|c|}{ Response Options (\%) } & \multirow{3}{*}{ Mean } \\
\hline & $\begin{array}{c}\text { Strongly Agree } \\
\text { (SA) }\end{array}$ & $\begin{array}{l}\text { Agree } \\
\text { (A) }\end{array}$ & $\begin{array}{c}\text { Unsure } \\
\text { (U) }\end{array}$ & $\begin{array}{l}\text { Disagree } \\
\text { (D) }\end{array}$ & $\begin{array}{c}\text { Strongly Disagree } \\
\text { (SD) }\end{array}$ & \\
\hline & Student & Student & Student & Student & Student & \\
\hline Estructura & 0 & 25.30 & 74.07 & 0.61 & 0 & 3.24 \\
\hline Procedimientos & 0 & 26.54 & 73.45 & 0 & 0 & 3.26 \\
\hline Métodos & 0 & 24.07 & 75.92 & 0 & 0 & 3.24 \\
\hline Técnicas & 0 & 27.77 & 72.22 & 0 & 0 & 3.28 \\
\hline Estrategias & 0 & 32.71 & 66.66 & 0.61 & 0 & 3.32 \\
\hline Interacción & 0 & 14.81 & 77.77 & 7.40 & 0 & 3.07 \\
\hline Contenido & 82.71 & 15.43 & 1.85 & 0 & 0 & 4.13 \\
\hline Recursos & 0 & 26.54 & 73.45 & 0 & 0 & 3.26 \\
\hline Total & 10.36 & 24.06 & 64.42 & 1.07 & $\mathbf{0}$ & 3.35 \\
\hline Category & & & 3.35 & ragely High & & \\
\hline
\end{tabular}

Table 4 shows the results of the didactic methodology dimension for the teaching of EFL, presenting a total of its indicators: procedures, methods, techniques, strategies, interaction, content and resources, through which students consider that $64.42 \%$ were unsure (U) about the effectiveness of the implementation of the indicators for the academic training process in the acquisition of the foreign language, while $24.06 \%$ agreed (A) on the application of the indicators as fundamental tools to improve the learning process; on the other hand, $10.36 \%$ stated that they strongly agreed (SA) with the treatment of this dimension and $1.07 \%$ state that they disagree (D), and the option strongly disagree (SD) did not obtain any answer. With respect to the arithmetic mean of the indicators, the students were within a category range of 3.35, which classified the effective implementation of the didactic methodology dimension as Averagely High for the teaching of English according to the range used. In this sense, the obtained score exhibited that the students only considered that there was an average achievement of the use of the didactic methodology, which gives rise to a significant opportunity for advancement from the theoretical and practical standpoint for the operation of English as a foreign language in the given setting. This uncertainty can be confirmed with the direct observations performed by the researcher in the natural ambiance of EFL professors through the use of a checklist template (see Appendix), whose percentage of occurrence reached $72 \%$ for the Grammar-Translation Method, being the most dominant among the other approaches: The Communicative Approach, TBL and PBL gained $17.5 \%$ and the Neurodidactic Approach achieved $18.25 \%$.

Table 5. Dimension: Neurodidactic Methodology for EFL Teaching

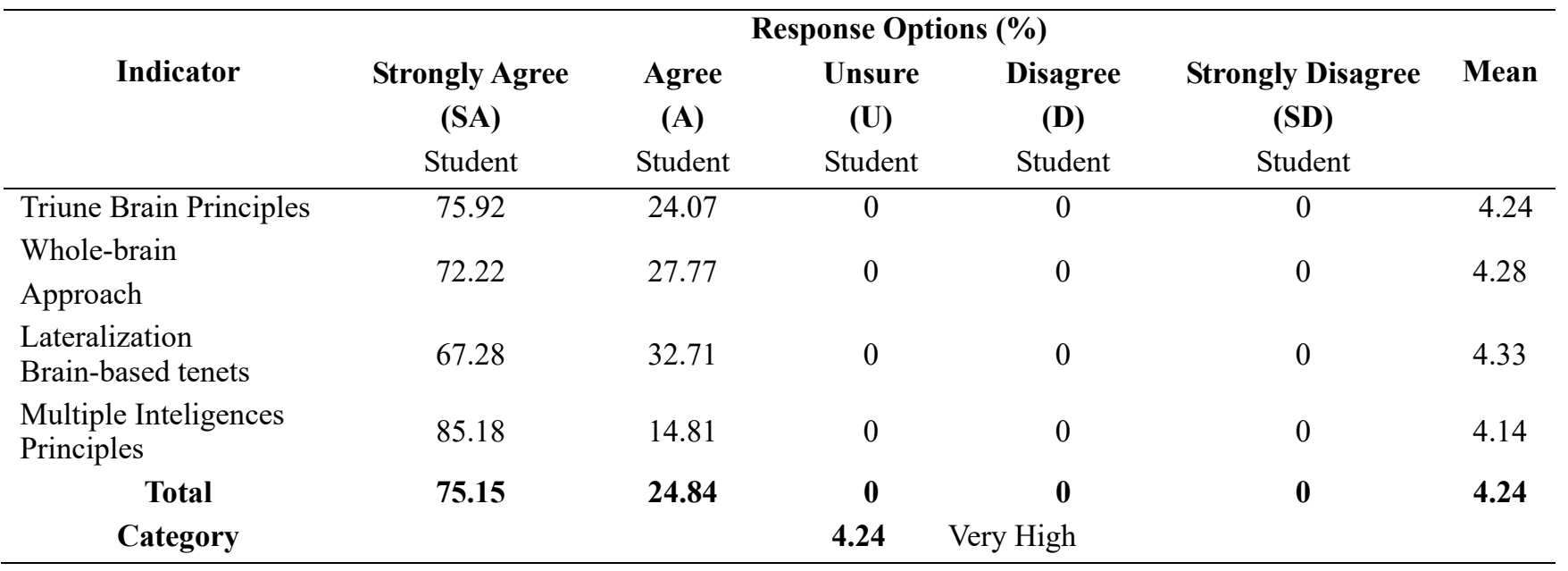


Table 5 shows the results of the neurodidactic methodology dimension for EFL teaching based on neuroscientific indicators, where the students consider that $75.15 \%$ strongly agreed (SA) that the methodology based on neuroscientific theories are effective in the pedagogical endeavor for the academic formation process in the use of the foreign language, while $24.84 \%$ agreed (A) that the implementation of neuroscientific tenets as fundamental devices to improve the learning processes; while the response options: undecided (U), disagree (D) and strongly disagree (SD) did not obtain an answer. With respect to the arithmetic mean of the indicators, the students were within a category range of 4.24, which categorized the effectiveness of the implementation of the neurodidactic methodology dimension as Very High for the teaching of EFL according to the range used. Regarding the arithmetic mean of this dimension, the students are within a category of the 4.24 range, which categorized as Very High the presence of the neuroscientific methodology applied. These data demonstrated the suitability of the neuroscientific impingement in the language pedagogy realm, according to the range used. In this respect, the percentage obtained shows a high degree of evidence as the students coincided in the way in which the brain-based methodology is consistent with an EFL pedagogical point of view and how it represents a new roadmap for meeting the needs of EFL instructors and learners. These outcomes result from the eclecticism of the Natural Approach and neuroscientific principles.

\section{Results and Discussion}

With these results, it is pertinent to affirm that the data provided by both instruments demonstrated the correlation between the methodology used by professors and the uncertainty expressed by the students. This can be a reasonable inference that accounts for the origin of the outlined problematic occurrence. The students could find an inconsistency between the rigidity of the university evaluation system and the quality of instruction; i.e., the level of academic demand is scarcely proportional to the quality of teaching imparted, thus causing them to either fail the course and/or drop out. Another variable that can be incidental is the level of professors' satisfaction regarding salary factors or the availability of teaching resources; these phenomena provide an opportunity for further research in the given context. Concerning the Grammar-Translation Method, Hago (2020) concluded in his case study that it has a negative impact on the learners' motivation because of the complexity of the English grammar, the lack of oral interaction, the strict focus on written skills and the passive attitude of the teachers (given that they are not required to speak the target language). Even though the Grammar-Translation Method may be effective for developing secondary skills, its validity for the development of primary communication seems obsolete due to its merely academic nature and goal and with the rise of innovative methods such as the Natural and Communicative Approaches.

The Natural Approach (Terrell \& Krashen, 1986) comprises second language acquisition principles and theories and a practical component with the classroom techniques and procedures that emphasize the experience over the explanation. In their proposal, the natural method attributes the most important function of language to communication and, consequently, it focuses on the teaching of communication skills. Meaning becomes the center of attention, the importance of vocabulary is emphasized, and grammar is displaced to a secondary realm. The lexicon is considered essential in the construction and interpretation of sentences. The techniques recommended by Terrell and Krashen are borrowed from other methods and are adapted to the principles of the natural method; for example: activities based on commands, the Total Physical Response Method, the Direct Method, the use of mimicry and gestures and context. However, according to the abovementioned statistical results, there is an unreliable attitude towards the assimilation of these naturalistic pedagogical procedures in the EFL classroom which creates a significant methodological gap between the Grammar-Translation Method and a neurodidactic approach.

While Krashen's Affective Filter Hypothesis (1981) asserts that success in acquiring a second language is associated with a variety of affective factors (motivation, self-confidence, anxiety), it is possible to agree and affirm that, although mechanical repetition activities are necessary, they only acquire cognitive value when they are impregnated with emotional connections and their real environment according to the postulate of Friedrich and Preiss (2003). In other words, the strength of a memory depends significantly on the emotional attitude in which such memory is acquired. Therefore, the development of the communicative performance is difficult to develop with the implementation of a master lecture approach or with methods lacking cognitive integration. For the abovementioned author, facial and body gestures and context play a major role when interacting with students. This aspect also facilitates the implementation of an inductive approach that introduces the emotional experience before explanation of linguistic contents, which results in favor of oral interaction. In addition, for these authors, this discipline constitutes a set of criteria and procedures that emerge from the contributions of neuroscience, and they are to advise curriculum development, especially in aspects such as selection, sequencing and organization of learning situations related to desired objectives, and that are built from the approaches of a 
pedagogy respectful of the complexity of human development.

The Natural Approach is linked to the neurodidactic model in a broad sense; while Snowling, Bishop y Stothard (2000) associate speech sound disorders (phonological and articulatory disorders) with subsequent reading deficits (cited in Spencer and Oleson, 2008), Krashen's Natural Order Hypothesis establishes the advantages of introducing the oral experience prior to providing the students with any structural explanation. This theoretical incorporation strengthens the assumption that aural and oral skill development should precede exposure to written codes and/or grammatical formulations. Moreover, the brain lateralization theory attests the dominance of the left hemisphere in processing verbal abilities, thus highlighting the importance of stimulating this cerebral area with emotional devices of the right hemisphere that act as a catalyst for the working memory through imagination, intuition, artistic sense, images and creativity. In other words, the right and left brain hemispheres form a synergy to perform distinct functions, but simultaneously complementary, indicating that in the same way the didactic planning should integrate a combination of both hemispherical requirements to address the natural acquisition of the target language in the brain. These neuro-cognitive coalescence is also directly related to the requirements of the optimal Comprehensible Input Hypothesis postulated by Krashen (1981), specifically through subconscious acquisition that takes place in the intuitive hemisphere versus conscious learning that occurs in the rational brain. With an appropriate approach, it is possible to optimize the teaching actions in the classroom so that the mental progressions that contribute to the formation of phonological patterns are effectively induced, thus preventing the fossilization of a faulty pronunciation due to the effect of the mother tongue over the target language. In addition, according to Mora (2013), another important aspect of neurodidactics is its interest in helping to detect psychological or brain processes that may interfere with learning and memory and with education itself. In other words, in addition to providing a new teaching model that enhances skills and talents, it also helps to predict cognition deficits that disable or reduce their abilities to read, write, do numbers or learn a foreign language. In turn, the assessment and predisposition of cognitive mechanisms and effective didactic procedures for developing orality are guaranteed, which have a positive effect on academic outcomes resulting in reduced failing cases and dropout rates.

Nevertheless, other than the observations and insights and expertise of the researcher and his 16 years of hands-on teaching experience, this analysis is limited to the perceptions of 1st year college students as to the methodologies implemented by their EFL professors in their regular schedules: eight hours a week and 16 weeks a semester. This study was restricted to the perception of students living temporarily in Pamplona, Norte de Santander from diverse facets of society. As a factor of external validity, the participants come from different regions of Colombia and from very distinct cultural customs and dialects. Data for this study were collected during the Spring of 2018.

Finally, this study develops a neurodidactic model that combines the fundamental principles of neuroscience, learning theories and EFL pedagogy in such a way that they address the methodological pitfalls that teachers face when engaging in a learning objective. In particular, not only does this amalgamation incorporate the neuroscience of learning and educational psychology, but also the major domains of cognition perceptual and retention issues. This model is also intended to complement the established special EFL didactic theory by drawing attention to the validity of brain research and its relevance in the praxis of language pedagogy.

\section{Design of the Neurodidactic Model for EFL Teaching}

\subsection{Conceptual Foundations}

In line with the generation of innovative educational practices and based on the analysis of germane learning theories, the Neurodidactic Model is developed, detailing its content, objectives, principles and syntax of the phases that constitute its structure. Table 6 specifies the didactic implications that underlie the elaboration of the model that is based upon educational, language and brain theories. In particular, the didactic implications are established in strategic and procedural terms that act as generators and regulators of methods, procedures and techniques that potentially advance the learning process according to individual and collective learning needs.

Through this scheme, an alternative methodology is presented in order to inform or at least disquiet educators on the understanding of didactic strategies that are designed based on physiological and functional knowledge of the brain and how it acquires language. A logical order is proposed taking into account the nature of the process. First, Diagnostic Strategies certainly take place prior to starting any didactic performance so as to make informed decisions on student potential cognitive needs. They provide neuroeducators with information that will allow them to understand and tailor appropriate planning and accommodations. Secondly, Socioemotional Strategies pervade the learning environment with a responsive predisposition that empowers the students' cognition. They can also be used throughout the process provided specific individual proclivity to fail is identified. Thirdly, with 
appropriate emotional environment, Neurocommunicative Strategies are used to provide comprehensible input and activate the Language Acquisition Device (LAD) that involves the activation of the whole brain respecting the specialization of each hemisphere for programming the linguistic forms subconsciously. They deal with the top-down mode that the brain uses to acquire language fluency while stimulating the procedural memory in meaningful situations. Fourthly, Operational Strategies detail the phonological aspects of the language for enhancing oral accuracy. They are in charge of activating the declarative memory since it involves attention to minutiae of the phonetic system. Appropriate implementation of these strategies will be reflected in effective listening and speaking skill development at a beginner's level.

The conception of the student for this model is a combination of behaviorism and constructivism considerations; even though they are antagonistic, both are necessary depending on the nature of the strategies and techniques used. Namely, the learner plays a behaviorist passive role when taking in comprehensible input in a given activity, not implying that their mental devices for verbal production remain unreceptive, quite the opposite, they are reflexive and in preparation mode as their cognition is actively processing the language meaningfully by means of kinesthetic procedures that trigger the perceptual channels of the brain. On the other hand, once the students have gained significant verbal exposure and their phonology starts shaping up in the left hemisphere with the assistance of an effective phonetic method, it is time to activate their dynamic role as constructivists of their own learning. The role of the neuroeducator, however, is reversed; while the student adopts a receptive attitude, the professor acts as an active, well-prepared, knowledgeable agent that leads the acquisition process escalating the level of oral complexity and making adjustments where necessary to meet individual needs. On the other hand, in order to stimulate attention and perception of oral codes, the use of material resources play an essential role in neurodidactics; a neuroeducator distinguishes the difference between tools and methods, and understands that tools are supporting aids that enhance the implementation of a method and not the method itself. An neuroeducator uses materials in a systematic manner and is aware that their appropriate implementation can accelerate and consolidate the achievement of the learning goal.

Table 6. Neuroscience and Special Didactics of Foreign Languages

\begin{tabular}{ll}
\hline Neuroscientific Theory & Description \\
\hline & $\begin{array}{l}\text { Sperry (1973) and McLean (1990) } \\
\text { explain the natural progression of brain }\end{array}$ \\
Triune Brain Principles & evolution: from the lowest zone the \\
& reptilian system is located (basic \\
& reasoning, routines, rituals), the limbic \\
& system constitutes the seat of emotional \\
& intelligence and the neocortex, made up of \\
& the hemispheres, develops rational \\
& intelligence.
\end{tabular}

Didactic Implications

Emphasis should be place on the use of communication strategies that involve three fundamental aspects of the Triune brain: routines, emotions, and basic reasoning. Didactic actions should favor an environment that generates pleasant experiences through the creation of communicative and operational habits representing a functional meaning for the construction of natural oral performance.

Herrmann (1991) integrates the hemispheric specialization and the triune brain, dividing the brain into 4 quadrants (A, B, C, D), two upper quadrants in the neocortex area and two lower quadrants in the limbic area. The characteristics of quadrant A belongs to the realistic logical thinkers; Quadrant B features tell us that this is the structured organizers quadrant. The characteristics of quadrant $\mathrm{C}$ indicate that they are humanitarian, emotional; the typologies in quadrant $\mathrm{D}$ point out that they are innovative, experimental, imaginative, synthesizers. The four quadrants, recombine and form four new modes of thought: quadrants $\mathrm{AB}$ realistic and common sense; quadrants $\mathrm{CD}$ the idealistic and kinesthetic; quadrants $\mathrm{AD}$
The whole brain model aligns the dominance of the quadrants with the occupational profile of the students. This allows the interplay with other disciplines while planning the micro curriculum since it favors the implementation of speaking communication skills, which are transversal to all fields of knowledge. In this way, an opportunity is presented to explore and take advantage of the students' own interests; the interaction with other disciplines which results in an added professional value. This advantageous assimilation is pedagogically incorporated through Content and Language Integrated Learning (CLIL). Of course, interdisciplinary teaching entails the interest and commitment of knowledgeable teachers. 
pragmatic, and quadrants $\mathrm{BC}$ instinctive and visceral.

Heller (2006) demonstrates the hyper-specialization of the cerebral hemispheres. The left hemisphere (LH) is the seat of language, logical reasoning and mathematics. The right hemisphere (RH) governs intuition, spatial relationships, image recognition. The LH analyzes and

Brain Lateralization Tenets

Multiple Intelligences Theory classifies information in schemes that already exist, that is, it processes information in specific areas that it later integrates. The $\mathrm{RH}$ processes new information and builds new schemes, these schemes will be shared with the LH, therefore, the $\mathrm{RH}$ participates in intermodal integration.

Gardner (1997) asserts that "we are all able to know the world through language, logical-mathematical analysis, spatial representation, musical thinking, the use of the body to solve problems or to make things, an understanding of other individuals and an understanding of ourselves, the comprehension of nature and the existence itself. Where individuals differ is in the strength of these intelligences and the ways in which such intelligences are invoked and combined to carry out different tasks, solve diverse problems and progress in various domains.
The teaching of a foreign language at elementary levels are based on didactic strategies that consider the application of methods, procedures and techniques that address orality from a balance between thinking, doing and feeling as integrated functional units that can be usable both for empowerment of both hemispheres and for the achievement of a communicative objective. An understanding of the left hemisphere, for example, reveals that it is possible to avoid the fossilization of the graphemic code of the mother tongue over the phonetic code of the target language by bypassing the angular gyrus through a segmental phonetic method.

Recognizing individual variation in student intellectual performance allows attention to be focused on areas that require emphatic operational training. This allows the selection of strategic didactic actions that enhance the development of the aural and oral brain devices through the programming of linguistic acquisition mental mechanisms for minimizing the incidence of the mother tongue code system. The understanding of differentiated needs facilitates the elaboration of a holistic instruction that accommodates individual distinctions and addresses collective characteristics.

\footnotetext{
5.2 Methodological Component: Modalities of Neurodidactic Strategies for the Teaching of Elementary English as a Foreign Language.

Table 7 summarizes the four strategic modalities that act as dynamic guidelines of the neurodidactic methodological model for the teaching of English as a foreign language in a university context at the elementary level. Each of these strategies (see figure 1.) includes methods, procedures and techniques that favor the development of EFL orality considering the neurocognitive principles that underpin neurodidactics, and therefore, the strategic actions of this proposal.
} 


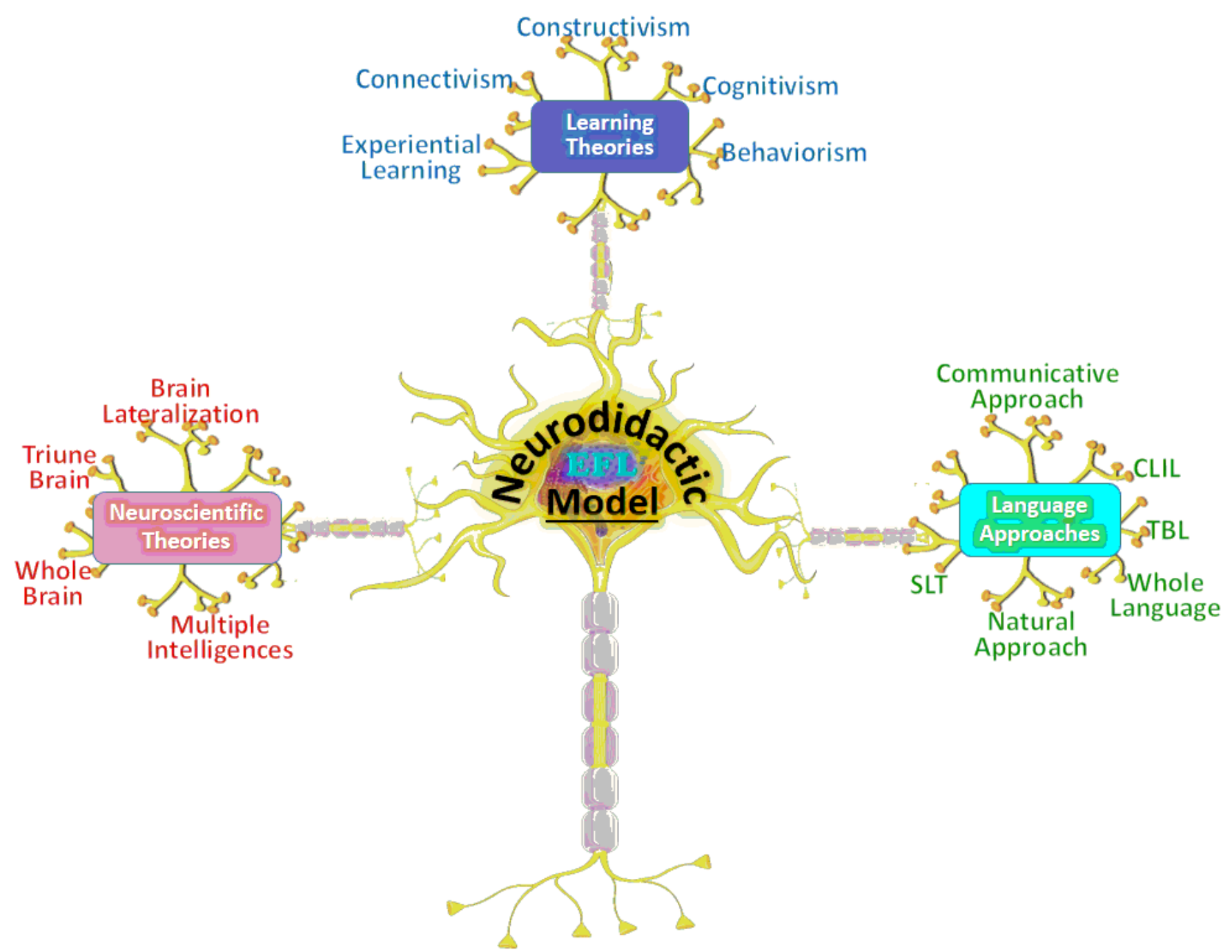

Figure 1. Neurograph of the Neurodidactic Model for EFL Teaching 


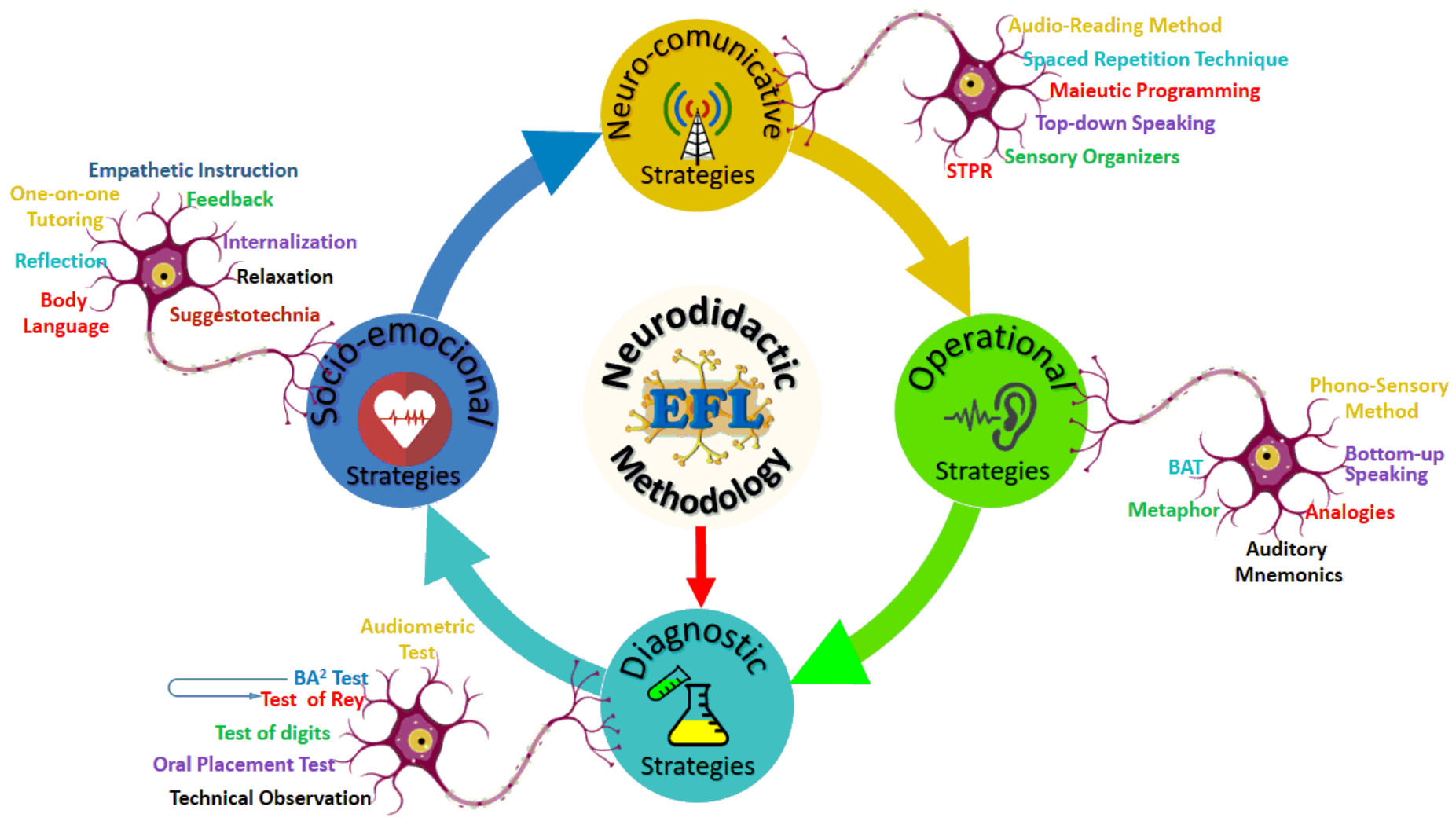

Figure 2. Neurograph of the Neurodidactic Methodology for Teaching Elementary EFL

Table 7. Modalities of neurodidactic strategies

\begin{tabular}{|c|c|}
\hline Modalities & Definition \\
\hline Diagnostic Strategies & $\begin{array}{l}\text { They consist of a set of neurocognitive tests whose aim is to identify the } \\
\text { strengths and weaknesses of students in terms of the performance of } \\
\text { primary communication skills and the learning capacity determined by the } \\
\text { memory system. Among them are: the Audimetric Test, the Barbosa } \\
\text { Articulatory Acquisition Test (BA2T), the Rey Verbal Learning Test, the } \\
\text { Digits Test, the Oral Classification Test and the Methodological } \\
\text { Observation for teacher's peer feedback. }\end{array}$ \\
\hline $\begin{array}{r}\text { Socio } \\
\text { Stı }\end{array}$ & $\begin{array}{l}\text { They are attitudinal and functional mechanisms that favor interaction, } \\
\text { memory and learning because they inhibit demotivation, apathy, tension, } \\
\text { and stress in situations of communicative skills acquisition. The following } \\
\text { can be distinguished in this group: empathic instruction, feedback, } \\
\text { internalization, relaxation, suggestotechnia, reflection, body language, } \\
\text { one-on-one tutoring. }\end{array}$ \\
\hline $\begin{array}{l}\text { lunicative } \\
\text { egies }\end{array}$ & $\begin{array}{l}\text { They constitute the use of methods and techniques that catalyze the } \\
\text { development of the skills underlying the primary communicative } \\
\text { performance, focusing on subconscious grammatical and phonological } \\
\text { accuracy and oral fluency in order to achieve an effective elementary } \\
\text { communicative level. Among these are: The Audio-reader method, Spaced } \\
\text { Repetition Technique, STPR, Top-down Speaking, Sensory Organizers, } \\
\text { Maieutic Programming. }\end{array}$ \\
\hline Operational Strategies & $\begin{array}{l}\text { They are made up of a series of procedures that optimize the mechanization } \\
\text { of phonological and articulatory precision increasing the opportunities of } \\
\text { exposure and cognitive integration for the development of the language } \\
\text { acquisition device (LAD). Among the operational strategies are: the } \\
\text { Phono-Sensory Method, BAT (Betterment of the Auditory Tact), analogies, } \\
\text { Auditory Mnemonics, Bottom-up Speaking, SLT. }\end{array}$ \\
\hline
\end{tabular}




\section{Conclusion}

By virtue of the objectives set together with the results and analyzes carried out in this research, the following conclusions are drawn:

With respect to the first objective: to identify the didactic methodology used by teachers in the English area that affect the acquisition and learning process in elementary students of the Foreign Languages Program, the data collection tools allowed to corroborate the correlation between the teaching approach used in the classroom and the level of student satisfaction in terms of instruction quality and skill development. This correspondence brings about the need to use different pedagogical strategies that facilitate acquisition and learning outcomes.

Successively, approaches to advance oral communicative performance of EFL beginner students were determined with the intention of recognizing the importance given to listening and speaking as pivotal skills in the administration of EFL methods and as working skills that guarantee a high performance of cognitive development and the foundation for secondary communication skills: reading and writing.

Likewise, it was possible to understand how cognitive performance associated with the development of orality has an effect on the advancement of oral fluency and accuracy through the use of verbal and articulatory acquisition strategies that account for the adequate disposition of mental processes and the functioning of the memory system while learning a foreign language.

Subsequently, a neurodidactic methodology is designed and proposed for the effective development of primary communication skills in elementary English students of the Foreign Languages Program of the University of Pamplona through the implementation of neurodidactic strategies in order to optimize the quality of teaching for the acquisition of English accuracy and fluency.

Finally, the design of the neurodidactic proposal seeks to establish a methodological structure based on four strategies that can be applied taking into consideration neuropsychological elements, as well as the cognitive peculiarities of the students. This methodological scheme has as its first strategy the cognitive diagnosis of the student, to then generate neurodidactic actions based on the other three strategies, so that adequate training is guaranteed laying language approaches along with the four neuroscientific theories as the ground work.

\section{Acknowledgements}

I would like to acknowledge the willingness of the Foreign Languages Program and Language and Communication Department Directors at the University of Pamplona for cooperating with the necessary allocation of the required courses for this research. Also, I extend my gratitude to my EFL colleagues who granted permission for the researcher to carry out unannounced lesson observations and to the EFL students of $1^{\text {st }}$ and $2^{\text {nd }}$ semesters who disinterestedly accepted the formal invitation to participate in this study. I am also grateful with the University of Pamplona, its Chancellor and Academic Vice Chancellor for the allotted hours in my teaching schedule to conduct educational research.

\section{References}

Bransford, J., Brown A., \& Cocking R. (2003). How People Learn: Brain, Mind, Experience and School. Washington D.C.: National Academy Press.

Conkan, D. (2018). Neurodidactics: The Selection Of Teaching Materials For German As A Foreign Language. 6th International Conference - "Education, Reflection, Development, Sixth Edition". https://doi.org/10.15405/epsbs.2019.06.50

Friedrich, G., \& Preiss G. (2003). Neurodidáctics. Mind and Brain, 4.

Gardner, H. (1997). Multiple Intelligences: The Theory in Practice. New York, NY.

González, C. (2016). Neuroeducación y lingüistica: una propuesta de aplicación a la enseñanza de la lengua materna. Universidad Complutense de Madrid. Madrid, España.

Hago, S. (2020). The Pros and Cons of the Grammar Translation Method on the Performance of Saudi EFL Learners. (A case study of the third class in Saudi secondary schools in Northern boarders). Jazan University, Saudi Arabia.

Heller, M. (2006). El Arte de Mediar con Todo el Cerebro. La Obra. Revista de Educación. Año 85, № 1006. Buenos Aires, Ediciones La Obra, enero/febrero de 2006. Retrieved from https://www.imaginaria.com.ar/17/8/educacion-inicial-la-obra.htm\#2

Herrmann, M. (1991). The creative brain. Búfalo: Brain books. 
https://doi.org/10.1002/j.2162-6057.1991.tb01140.x

Hurtado, J. (2010). El proyecto de investigación. Compresión holística de la metodología y la investigación. Ediciones Quiron Bogotá - Caracas.

Jensen, E. (2004). Cerebro y Aprendizaje. Competencias e Implicaciones Educativas. Madrid. Narcea. S.A. Ediciones.

Krashen, S. (1981). Second language acquisition and second language learning. 1st Ed. New York, Pergamon Press.

Krashen, S., \& Terrell, T. (1983). The natural approach: language acquisition in the classroom. Oxford: Pergamon.

Mclean, P. (1990). Education and brain. Chicago Press.

Mora, F. (2013). Neuroeducación. Mind, Brain and Education.

Rost, M. (2011). Teaching and researching listening. Applied linguistics in action Series. Pearson Education Limited 2002, 2011.

Rukminingsih, R. (2018). Integrating Neurodidactics Stimulation into Blended Learning in Accomodating Students English Learning in EFL Setting. ACE Conference 2018: IAFOR. Retrieved from https://papers.iafor.org/submission 4210

Sperry, R. (1973). Síndrome of Hemispheric Desconnection. Segundo Congreso Panamericano de Neurología, Puerto Rico.

Volkmar, F. R. (2013). Encyclopedia of Autism Spectrum Disorders: Direct Observation. Springer, New York, USA. https://doi.org/10.1007/978-1-4419-1698-3_1758 


\section{Appendix}

\section{Foreign Language Observation Checklist Template}

\begin{tabular}{|c|c|c|c|c|}
\hline Class Structure & $\begin{array}{c}4 . \\
\text { Excellent }\end{array}$ & $\begin{array}{c}3 . \\
\text { Acceptable }\end{array}$ & $\begin{array}{l}\text { 2. Could } \\
\text { Improve }\end{array}$ & $\begin{array}{l}\text { 1. Not } \\
\text { Observed }^{*}\end{array}$ \\
\hline 1. Reviews previous lesson's course content & $\mathrm{O}$ & $\mathrm{O}$ & $\mathrm{O}$ & $\mathrm{O}$ \\
\hline 2. Gives overview of lesson's course content & $\mathrm{O}$ & $\mathrm{O}$ & O & $\mathrm{O}$ \\
\hline 3. Summarizes course content covered & $\mathrm{O}$ & $\mathrm{O}$ & $\mathrm{O}$ & O \\
\hline 4. Directs student preparation for next class & $\mathrm{O}$ & O & $\mathrm{O}$ & $\mathrm{O}$ \\
\hline $\begin{array}{l}\text { 5. Evidences the main sections of a lesson (Presentation - Practice } \\
\text { - Assessment) }\end{array}$ & $\mathrm{O}$ & $\mathrm{O}$ & O & $\mathrm{O}$ \\
\hline AVERAGE & \multicolumn{4}{|c|}{$1.8=$ Could Improve } \\
\hline
\end{tabular}

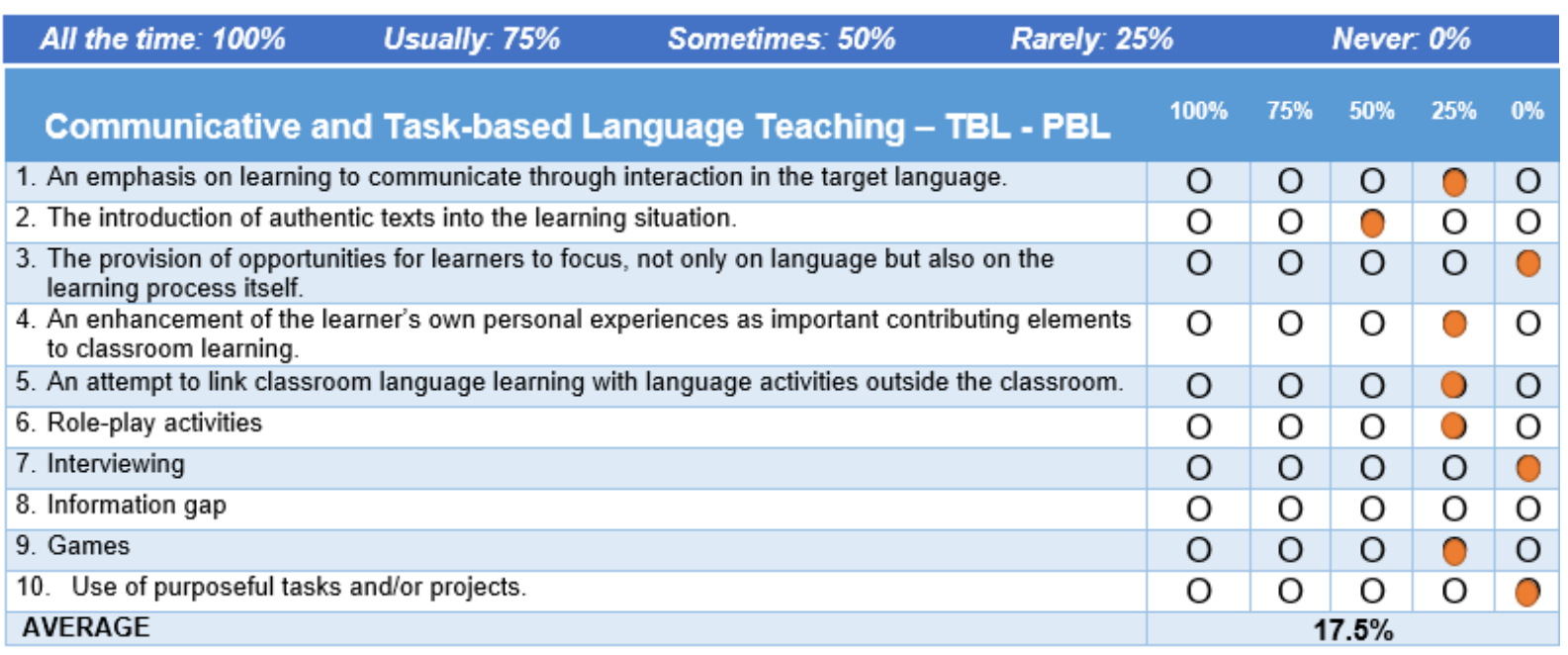

\section{Grammar-Translation Method}

1. The instruction is based on lecturing activities

\begin{tabular}{|c|c|c|c|c|}
\hline $\mathrm{O}$ & 0 & $\mathrm{O}$ & $\mathrm{O}$ & $\mathrm{O}$ \\
\hline 0 & $\mathrm{O}$ & $\mathrm{O}$ & $\mathrm{O}$ & $\mathrm{O}$ \\
\hline $\mathrm{O}$ & $\mathrm{O}$ & $\mathrm{O}$ & 0 & $\mathrm{O}$ \\
\hline 0 & $\mathrm{O}$ & $\mathrm{O}$ & $\mathrm{O}$ & $\mathrm{O}$ \\
\hline $\mathrm{O}$ & 0 & $\mathrm{O}$ & $\mathrm{O}$ & $\mathrm{O}$ \\
\hline $\mathrm{O}$ & 0 & $\mathrm{O}$ & $\mathrm{O}$ & $\mathrm{O}$ \\
\hline $\mathrm{O}$ & 0 & $\mathrm{O}$ & $\mathrm{O}$ & $\mathrm{O}$ \\
\hline $\mathrm{O}$ & $\mathrm{O}$ & $\mathrm{O}$ & 0 & $\mathrm{O}$ \\
\hline 0 & $\mathrm{O}$ & $\mathrm{O}$ & $\mathrm{O}$ & $\mathrm{O}$ \\
\hline $\mathrm{O}$ & 0 & $\mathrm{O}$ & $\mathrm{O}$ & $\mathrm{O}$ \\
\hline
\end{tabular}




\begin{tabular}{|c|c|c|c|c|c|}
\hline Neurodidactic Methodology & $100 \%$ & $75 \%$ & $50 \%$ & $25 \%$ & $0 \%$ \\
\hline 1. Provides brain-based designed materials & $\mathrm{O}$ & $\mathrm{O}$ & $\mathrm{O}$ & $\mathrm{O}$ & O \\
\hline 2. Employs non-lecture learning activities (i.e. small group discussion, student-led activities) & $\mathrm{O}$ & $\mathrm{O}$ & $\mathrm{O}$ & O & $\mathrm{O}$ \\
\hline 3. Invites class discussion and input from a variety of students & $\mathrm{O}$ & $\mathrm{O}$ & $\mathrm{O}$ & 0 & $\mathrm{O}$ \\
\hline 4. Employs other tools/instructional aids (i.e. flashcards, ICT, video, LCD projector) & $\mathrm{O}$ & $\mathrm{O}$ & $\mathrm{O}$ & $\mathrm{O}$ & $\mathrm{O}$ \\
\hline 5. Employs an inductive method (experience before explanation) & $\mathrm{O}$ & $\mathrm{O}$ & $\mathrm{O}$ & 0 & $\mathrm{O}$ \\
\hline 6. Modeling is used for access & $\mathrm{O}$ & $\mathrm{O}$ & $\mathrm{O}$ & $\mathrm{O}$ & $\mathrm{O}$ \\
\hline 7. Teaching techniques that facilitate different learning styles & $\mathrm{O}$ & $\mathrm{O}$ & $\mathrm{O}$ & 0 & $\mathrm{O}$ \\
\hline 8. Employs neurodidactic strategies ( $\mathrm{O}$ : Mnemonics M: Mind maps S: awareness raising) & $\mathrm{O}$ & $\mathrm{O}$ & $\mathrm{O}$ & $\mathrm{O}$ & 0 \\
\hline 9. Relates concepts to students' experience & $\mathrm{O}$ & $\mathrm{O}$ & 0 & $\mathrm{O}$ & $\mathrm{O}$ \\
\hline 10. The target language is encouraged and used exclusively & $\mathrm{O}$ & $\mathrm{O}$ & $\mathrm{O}$ & 0 & $\mathrm{O}$ \\
\hline 11. The teacher promotes phonological accuracy & $\mathrm{O}$ & $\mathrm{O}$ & $\mathrm{O}$ & $\mathrm{O}$ & 0 \\
\hline 12. Appropriate correction and feedback techniques are used & $\mathrm{O}$ & $\mathrm{O}$ & 0 & $\mathrm{O}$ & $\mathrm{O}$ \\
\hline 13. Learning strategies are encouraged to be used at home & $\mathrm{O}$ & $\mathrm{O}$ & $\mathrm{O}$ & $\mathrm{O}$ & 0 \\
\hline 14. Pronunciation methods are used to enhance accuracy & $\mathrm{O}$ & $\mathrm{O}$ & $\mathrm{O}$ & $\mathrm{O}$ & O \\
\hline 15. Neuro-communicative techniques are employed for developing oral fluency & $\mathrm{O}$ & $\mathrm{O}$ & $\mathrm{O}$ & $\mathrm{O}$ & O \\
\hline 16. The teacher raises the level of student attention (position, moves...) & $\mathrm{O}$ & $\mathrm{O}$ & O & $\mathrm{O}$ & $\mathrm{O}$ \\
\hline 17. Teacher body language is appropriate & $\mathrm{O}$ & $\mathrm{O}$ & O & $\mathrm{O}$ & $\mathrm{O}$ \\
\hline 18. Rapport, motivation is in evidence (learning atmosphere and mutual respect) & $\mathrm{O}$ & O & $\mathrm{O}$ & $\mathrm{O}$ & $\mathrm{O}$ \\
\hline 19. Demonstrates awareness of individual student learning needs & $\mathrm{O}$ & $\mathrm{O}$ & $\mathrm{O}$ & O & $\mathrm{O}$ \\
\hline 20. Selection of learning experiences appropriate to level of learning & $\mathrm{O}$ & O & $\mathrm{O}$ & $\mathrm{O}$ & $\mathrm{O}$ \\
\hline AVERAGE & \multicolumn{5}{|c|}{$18.25 \%$} \\
\hline
\end{tabular}

\section{Copyrights}

Copyright for this article is retained by the author(s), with first publication rights granted to the journal.

This is an open-access article distributed under the terms and conditions of the Creative Commons Attribution license (http://creativecommons.org/licenses/by/4.0/). 